\title{
Dietary spray-dried plasma improves intestinal morphology of mated female mice under stress condition
}

Yanhong Liư ${ }^{1 \dagger}$, Jeehwan Choe ${ }^{2 \dagger}$, Sheena Kim², Byeonghyeon Kim², Joy M. Campbell ${ }^{3}$, Javier Polo ${ }^{3}$, Joe D. Crenshaw ${ }^{3}$, James E. Pettigrew ${ }^{4^{*}}$ and Minho Song ${ }^{2^{*}}$ (D)

\begin{abstract}
Background: Stress causes inflammation that impairs intestinal barrier function. Dietary spray-dried plasma (SDP) has recognized anti-inflammatory effects and improvement of gut barrier function. Therefore, the purpose of this study was to investigate the effects of dietary SDP on intestinal morphology of mated female mice under stress condition.

Results: Villus height, width, and area of small intestines were low on gestation day (GD) 3 or 4 under stress conditions, and higher later (Time, $P<0.05$ ). Crypt depth of colon was low on GD 4 and higher later (Time, $P<0.05)$. Meanwhile, the SDP treatments improved $(P<0.05)$ intestinal morphology, indicated by increased villus height, villus width, villus area, and ratio between villus height and crypt depth of small intestines and crypt depth of colon, and by decreased crypt depth of small intestines, compared with the control diet. The SDP treatments also increased $(P<0.05)$ the number of goblet cells in intestines compared with the control diet. There were no differences between different levels of SDP.
\end{abstract}

Conclusion: Dietary SDP improves intestinal morphology of mated female mice under stress condition.

Keywords: Intestinal morphology, Mated female mice, Spray-dried plasma, Stress

\section{Background}

Spray-dried plasma (SDP) is one of additives in swine diets [1-3] and contains high protein with balanced contents of amino acids and various physiological components, such as immunoglobulins, peptides, glycoproteins, and others [4], that contribute to modulation of microbial populations [5, 6], immune responses and inflammation $[4,7,8]$, and intestinal morphology $[8,9]$, and others [4].

Based on these beneficial effects, SDP is typically used in nursery pig diets to maximize growth rate and to minimize health issues [1-3]. Previous research also showed that dietary SDP improved reproductive performance of sows under some stress

\footnotetext{
* Correspondence: jepettig@illinois.edu; mhsong@cnu.ac.kr

${ }^{\dagger}$ Equal contributors

${ }^{4}$ Department of Animal Sciences, University of Illinois, Urbana, IL, USA

${ }^{2}$ Department of Animal Science and Biotechnology, Chungnam National

University, Daejeon, South Korea

Full list of author information is available at the end of the article
}

conditions $[10,11]$ and pregnancy rate of mated female mice under transport stress [2].

Generally, various stressors can cause local or systemic inflammation $[12-14]$, resulting in the impairment of intestinal barrier function [15-17] and detrimental effects on animal performance and health $[18,19]$. It is well known that dietary SDP attenuates inflammation, strengthens intestinal barrier function, and improves intestinal morphology $[9,20-22]$. Therefore, the objective of present study was to determine whether dietary SDP provides beneficial effects on gut health, mainly intestinal morphology, of mated female mice under transport stress.

\section{Methods}

The experiment was conducted in the mouse facility of the Institute for Genomic Biology building at the University of Illinois at Urbana-Champaign, IL, USA. 
The mouse model of poor reproductive success used in this experiment was the same one used in the previous studies [2]. The levels of SDP (1 and 8\%) in the diet were chosen for this experiment based on the results from the previous studies [2].

\section{Animals, housing, diets, and experimental design}

A total of 156 mated female mice (C57BL/6 strain; $16.4 \pm 1.1 \mathrm{~g} \mathrm{BW}$ ) were shipped from a vendor (The Jackson Laboratory, Bar Harbor, ME, USA) to the university facility (Urbana, IL, USA) on the day the vaginal plug was found (gestation day [GD] 1) and arrived at the IL facility on GD 3 after $2 \mathrm{~d}$ transport by air and ground. When the mice arrived at the facility, they were weighed and housed in individual cages with controlled temperature $\left(23^{\circ} \mathrm{C}\right)$, humidity $(40 \%)$, and a $12 \mathrm{~h}$ light and dark cycle. They were immediately and randomly assigned to dietary treatments $(0$, 1 , and $8 \%$ SDP in the diet for CON, SDP1, and SDP8, respectively) and allowed free access to feed and water. The diets were formulated to meet or exceed NRC [23] estimates of nutrient requirements of mice and to have similar metabolizable energy, crude protein, amino acids levels, and no antibiotics (Table 1). The diets were pelleted without heating using a pellet press. The SDP was from bovine blood (APC, Inc., Ankeny, IA, USA).

\section{Sample collections and analyses}

As an initial group, 12 randomly selected mice were weighed and euthanized by $\mathrm{CO}_{2}$ immediately after they arrived at our facility on GD 3 . The rest of the mice were also weighed and euthanized by $\mathrm{CO}_{2} ; 12$ mice per dietary treatment each day from GD 4 to 7. After euthanasia, the abdominal cavity was opened to collect intestine samples: duodenum, jejunum, ileum, and colon. For analysis of intestinal morphology, each section $(3 \mathrm{~cm})$ of intestine was fixed in $10 \%$ buffered formalin. The processing of intestine samples was based on the reports by $\mathrm{Yi}$ et al. [22] and Balan et al. [24]. The fixed samples were embedded in paraffin, sectioned at $5 \mu \mathrm{m}$ thickness, and stained with hematoxylin and eosin. The slides were scanned by NanoZoomer Digital Pathology System (Hamamatsu Co., Bridgewater, NJ, USA). All measurements of scanned slides were conducted using the associated NDP view software. Six straight and integrated villi and their associated crypts were selected to measure intestinal morphology (villus height, width, and area, crypt depth, ratio between villus height and crypt depth, and number of goblet cells).
Table 1 Ingredient composition of experimental diets

\begin{tabular}{llll}
\hline & \multicolumn{3}{l}{ Dietary treatments ${ }^{\mathrm{a}}$} \\
\cline { 2 - 4 } Item & CON & SDP1 & SDP8 \\
\hline Ingredients, \% & 53.10 & 50.67 & 33.68 \\
Dried skim milk & 19.90 & 21.32 & 31.25 \\
Corn starch & 10.00 & 10.00 & 10.00 \\
Sucrose & - & 1.00 & 8.00 \\
Spray-dried plasma & & 7.00 & 7.00 \\
Soybean oil & 7.00 & 5.00 & 5.00 \\
Cellulose & 5.00 & 3.50 & 3.50 \\
AlN-93 MX & 3.50 & 1.00 & 1.00 \\
AIN-93 VX & 1.00 & 0.26 & 0.32 \\
DL-methionine & 0.25 & 0.25 & 0.25 \\
Choline bitartrate & 0.25 & & \\
Calculated energy and nutrient levels & 3483 & 3492 & 3558 \\
ME, kcal/kg & 18.28 & 18.25 & 18.00 \\
Crude protein, \% & 4.44 & 4.33 & 3.57 \\
Ash, \% & 1.18 & 1.14 & 0.94 \\
Ca, \% & 0.70 & 0.70 & 0.64 \\
P, \% & & &
\end{tabular}

${ }^{a} \mathrm{CON}=$ control diet; SDP1 $=1 \%$ spray-dried plasma diet; SDP8 $=8 \%$ spray-dried plasma diet

${ }^{\mathrm{b} T}$ The SDP was from bovine blood (AP 920; APC, Inc., Ankeny, IA, USA)

'Dyets, Inc., Bethlehem, PA, USA. Provided as milligrams per kilogram of diet: calcium, 5000; phosphorus, 1561; potassium, 3600; sodium, 1019; chloride, 1571; sulfur, 300; magnesium, 507; iron, 35; copper, 6; manganese, 10; zinc, 30; chromium, 1 ; iodine, 0.2 ; selenium, 0.15 ; fluorine, 1 ; cobalt, 0.5 ; molybdenum, 0.15 ; silicon, 5 ; nickel, 0.5 ; lithium, 0.1 ; vanadium, 0.1

${ }^{\mathrm{d} D y e t s, ~ I n c ., ~ B e t h l e h e m, ~ P A, ~ U S A . ~ P r o v i d e d ~ p e r ~ k i l o g r a m ~ o f ~ d i e t: ~ t h i a m i n ~}$ $\mathrm{HCl}, 6 \mathrm{mg}$; riboflavin, $6 \mathrm{mg}$; pyridoxine $\mathrm{HCl}, 7 \mathrm{mg}$; niacin, $30 \mathrm{mg}$; calcium pantothenate, $16 \mathrm{mg}$; folic acid, $2 \mathrm{mg}$; biotin, $0.2 \mathrm{mg}$; cyanocobalamin (vitamin $\left.B_{12}\right), 25 \mu \mathrm{g}$; vitamin A palmitate, $4000 \mathrm{IU}$; vitamin $\mathrm{E}$ acetate, $75 \mathrm{IU}$; vitamin $\mathrm{D}_{3}, 1000 \mathrm{IU}$; vitamin $\mathrm{K}_{1}, 0.75 \mathrm{mg}$

\section{Statistical analyses}

Data were analyzed using the PROC GLM procedure of SAS (SAS Inst. Inc., Carry, NC, USA) in a completely randomized design. The experimental unit was the mouse. For all measurements, the statistical model included effects of diet, time, and their interaction. In addition, pair-wise comparisons were performed among dietary treatments when a main effect of diet was found. The results are given as means \pm SE. Statistical significance and tendency were considered at $P<0.05$ and $0.05 \leq P<0.10$, respectively.

\section{Results and discussion}

Villus height, width, and area of all sections of small intestines were low on GD 3 or 4 under stress conditions, and higher later (Time, $P<0.05$; except villus height of duodenum, Fig. 1). Crypt depth of colon 


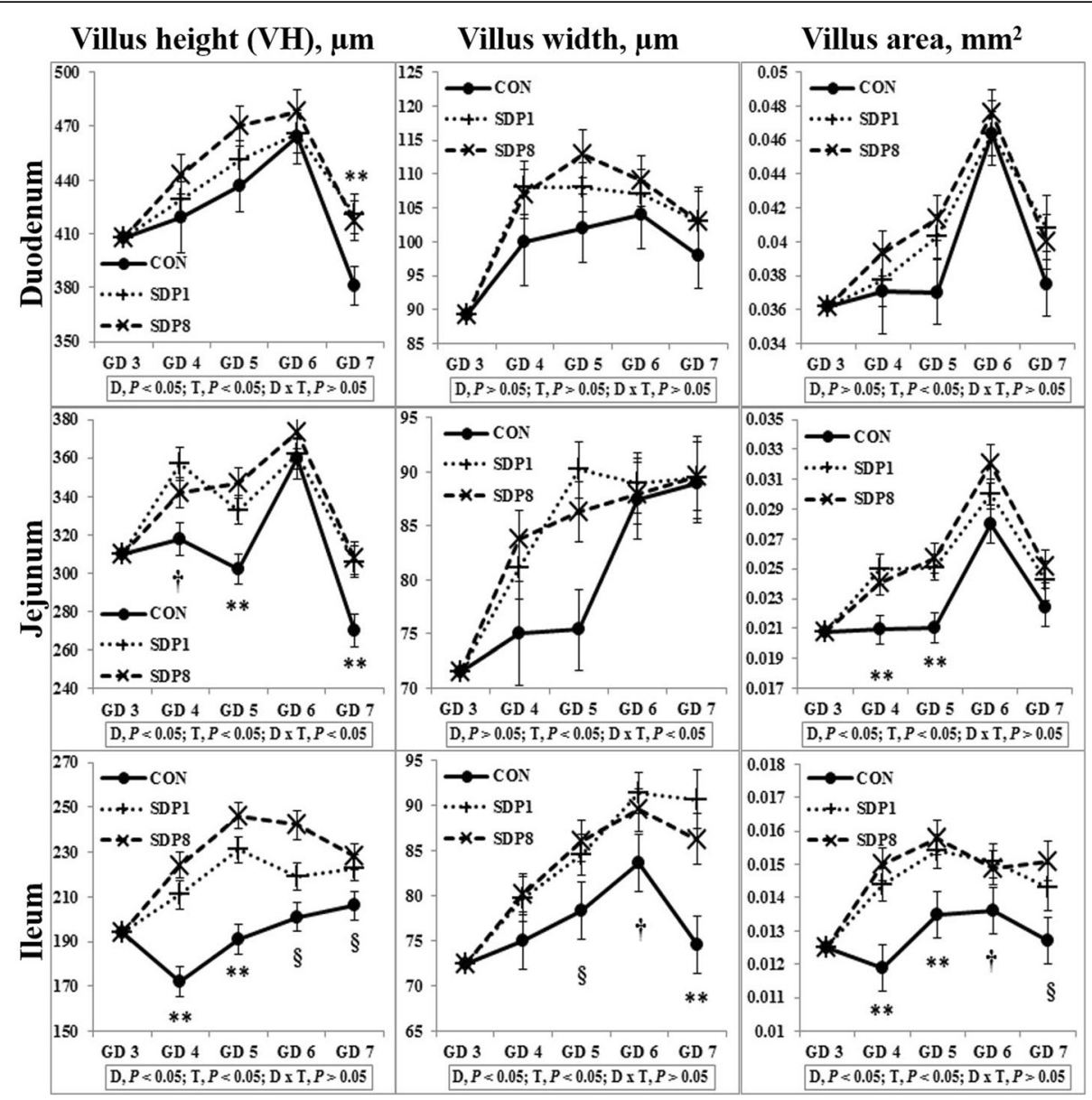

Fig. 1 Villus height, width, and area in the small intestinal tract of mated female mice fed experimental diets. Values are means $\pm S E ; n=12$ for GD 3, n=7-12 for each treatment (GD 4 through GD 7); CON = control diet, SDP1 $=1 \%$ spray-dried plasma diet, SDP8 $=8 \%$ spray-dried plasma diet. $\mathrm{D}$, diet; $\mathrm{T}$, time; $\mathrm{D} \times \mathrm{T}$, interaction between diet and time. ${ }^{* *}$ Different between CON and each other treatment (SDP1 and 8), $P<0.05$. §Different between CON and SDP 8, $P<0.05$. †Different between CON and SDP1, $P<0.05$. No differences were found between SDP1 and SDP8

was low on GD 4 under stress condition, and higher later (Time, $P<0.05$ ), but there was no consistent time pattern of small intestinal crypt depth (Fig. 2). The SDP treatments improved $(P<0.05)$ intestinal morphology in all sections of intestines, indicated by increased villus height, villus width, villus area, and ratio between villus height and crypt depth of small intestines and crypt depth of colon and by decreased crypt depth of small intestines, compared with the CON (Figs. 1 and 2). The SDP treatments also increased $(P<0.05)$ the number of goblet cells in all sections of intestines compared with the CON (Fig. 3). There were no differences between SDP1 and SDP8 (Figs. 1, 2, and 3). Measurements of intestinal morphology showed that inflammation, perhaps caused by stress, diminished as over time after arrival. Stress may be detrimental to structural integrity of the intestine as shown by reduction of villus height and crypt depth [25-27], but may not influence it if stress is not acute [27-29]. Therefore, transport stress may have compromised the mucosal integrity at arrival. Meanwhile, feeding SDP improved intestinal morphology in the present experiment, in agreement with the results from previous studies using pigs under inflammation [20-22] and rats under normal conditions [24]. This benefit may derive from attenuation of inflammation by SDP, enhancement of gut barrier function by SDP, or both $[9,16]$. The present experiment also shows that feeding SDP increases the number of goblet cells in all intestinal sections, in contrast to the lack of SDP effect in a previous study using pigs [30], suggesting a potential associated increase in mucin secretion and perhaps, therefore, in strengthening of the gut barrier function. 


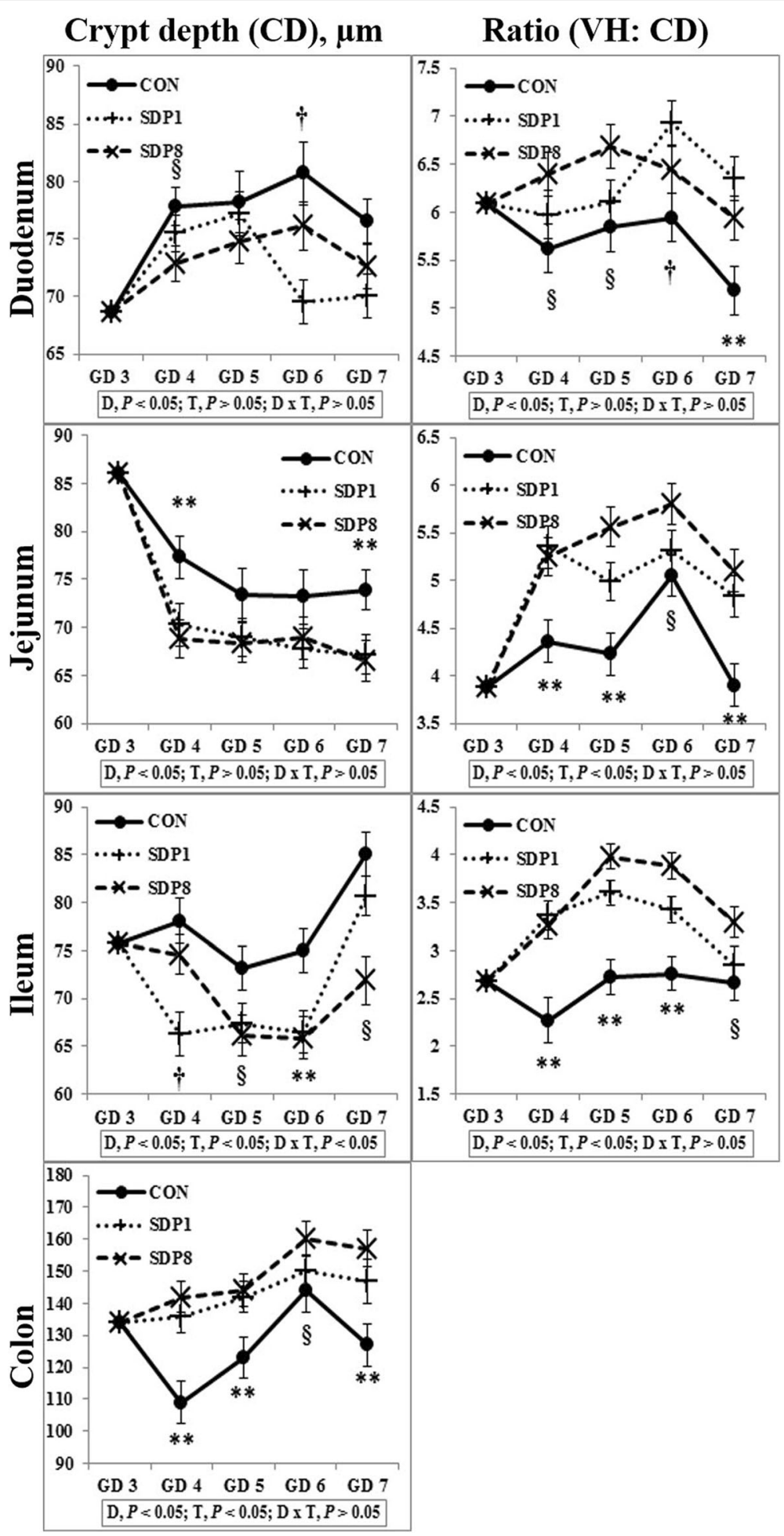

Fig. 2 Crypt depth and ratio between villus height and crypt depth in the intestinal tract of mated female mice fed experimental diets. Values are means $\pm \mathrm{SE} ; \mathrm{n}=12$ for GD 3, $\mathrm{n}=7-12$ for each treatment (GD 4 through GD 7); CON = control diet, SDP1 = 1\% spray-dried plasma diet, SDP8 $=8 \%$ spray-dried plasma diet. D, diet; $T$, time; $D \times T$, interaction between diet and time. ** Different between CON and each other treatment (SDP1 and 8), $P<0.05$. §Different between CON and SDP 8, $P<0.05$. †Different between CON and SDP1, $P<0.05$. No differences were found between SDP1 and SDP8 
A

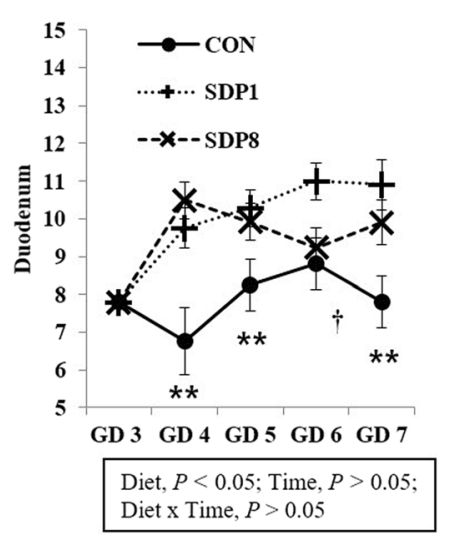

C

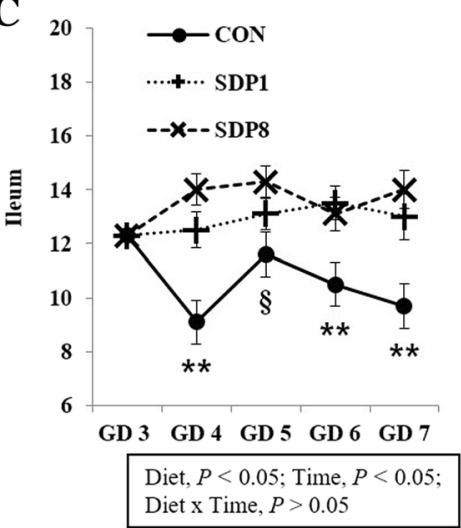

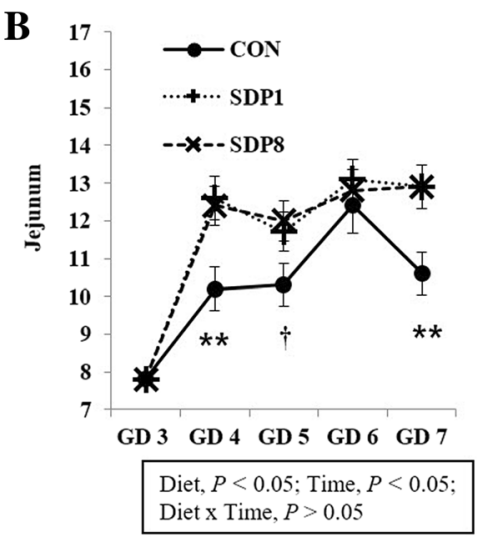

D

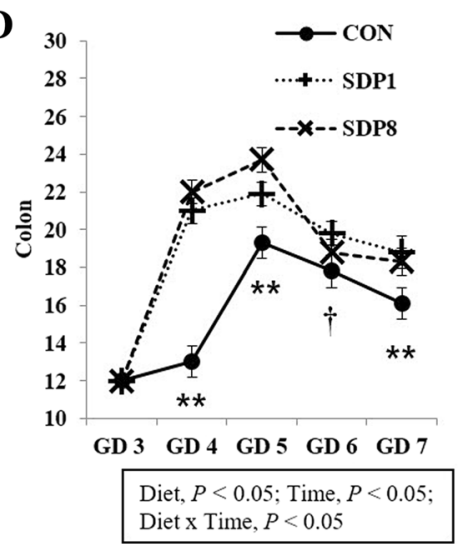

Fig. 3 Number of goblet cells in the intestinal tract of mated female mice fed experimental diets. Values are means \pm SE; $n=12$ for $G D$ 3, $n=7-12$ for each treatment (GD 4 through GD 7); CON = control diet, SDP1 = 1\% spray-dried plasma diet, SDP8 =8\% spray-dried plasma diet. (a) Duodenum, (b) Jejunum, (c) lleum, (d) Colon. ${ }^{* *}$ Different between CON and each other treatment (SDP1 and 8), $P<0.05$. §Different between CON and SDP 8, $P<0.05$. tDifferent between CON and SDP1, $P<0.05$. No differences were found between SDP1 and SDP8

\section{Conclusion}

Dietary SDP strengthened the integrity of intestinal morphology of mated female mice under stress condition.

\section{Abbreviations}

GD: Gestation day; SDP: Spray-dried plasma.

\section{Acknowledgements}

This work was financially supported by the fund from dispatch overseas program of Chungnam National University in 2018.

\section{Funding}

This work was financially supported by the fund from dispatch overseas program of Chungnam National University in 2018.

\section{Availability of data and materials}

The datasets generated and/or analyzed during the current study are only available from the corresponding author on reasonable request.

\section{Authors' contributions}

All authors participated in the preparation, experiments, and discussion of the manuscript. YL and JC focused on the writing of manuscript and JEP and MS supervised all processes through performing the experiment to writing the manuscript. The final version of the manuscript was approved by all authors.
Ethics approval and consent to participate

The protocol for this experiment was reviewed and approved by the Institutional Animal Care and Use Committee of the University of Illinois at Urbana-Champaign (UIUC IACUC Approval \#11111).

\section{Competing interests}

The authors declare that they have no competing interests.

\section{Publisher's Note}

Springer Nature remains neutral with regard to jurisdictional claims in published maps and institutional affiliations.

\section{Author details}

'Department of Animal Science, University of California, Davis, CA, USA. ${ }^{2}$ Department of Animal Science and Biotechnology, Chungnam National University, Daejeon, South Korea. ${ }^{3}$ APC Inc., Ankeny, IA, USA. ${ }^{4}$ Department of Animal Sciences, University of Illinois, Urbana, IL, USA.

Received: 26 January 2018 Accepted: 23 April 2018 Published online: 04 June 2018

\section{References}

1. Coffey RD, Cromwell GL. Use of spray-dried animal plasma in diets for weanling pigs. Pig News Info. 2001;22:39-48.

2. Song M, Liu Y, Lee JJ, Che TM, Soares-Almeida JA, Chun JL, Cambell JM, Polo J, Crenshaw JD, Seo SW, Pettigrew JE. Spray-dried plasma attenuates 
inflammation and improves pregnancy rate of mated female mice. J Anim Sci. 2015;93:298-305.

3. Jang K, Kim J, Kim S, Jang Y, Lee J, Kim Y, Park J, Kim Y, Song M. Value of spray-dried plasma as a supplement to swine diets. Korean J Agric Sci. 2016; 43:14-20.

4. Pettigrew JE. Reduced use of antibiotic growth promoters in diets fed to weanling pigs: dietary tools, part 1. Anim Biotechnol. 2006;17:207-15.

5. Nollet H, Deprez P, Van Driessche E, Muylle E. Protection of just weaned pigs against infection with F18+ Escherichia coli by non-immune plasma powder. Vet Microbiol. 1999;65:37-45.

6. Niewold TA. The nonantibiotic anti-inflammatory effect of antimicrobial growth promoters, the real mode of action? A Hypothesis Poul Sci. 2007;86: 605-9.

7. Pérez-Bosque A, Pelegrí C, Vicario M, Castell M, Russell LE, Campbell JM, Quigley JD, Polo J, Amat C, Moretó M. Dietary plasma protein affects the immune response of weaned rats challenged with $S$. aureus superantigen $B$. J Nutr. 2004;134:2667-72.

8. Peace RM, Campbell JM, Polo J, Crenshaw JD, Russell LE, Moeser RL. Spraydried porcine plasma influences intestinal barrier function, inflammation, and diarrhea in weaned pigs. J Nutr. 2011;141:1312-7.

9. Pérez-Bosque A, Amat C, Polo J, Campbell JM, Crenshaw JD, Russell LE, Moretó M. Spray-dried animal plasma prevents the effects of Staphylococcus aureus enterotoxin B on intestinal barrier function in weaned rats. J Nutr. 2006:136:2838-43

10. Crenshaw JD, Boyd RD, Campbell JM, Russell LE, Moeser RL, Wilson ME. Lactation feed disappearance and weaning to estrus interval for sows fed spray-dried plasma. J Anim Sci. 2007;85:3442-53.

11. Frugé ED, Roux ML, Lirette RD, Bidner TD, Southern LL, Crenshaw JD. Effects of dietary spray-dried plasma protein on sow productivity during lactation. J Anim Sci. 2009;87:960-4.

12. Pérez-Bosque A, Miró L, Polo J, Russell LE, Campbell JM, Weaver E, Crenshaw JD, Moretó M. Dietary plasma proteins modulate the immune response of diffuse gut-associated lymphoid tissue in rats challenged with Staphylococcus aureus enterotoxin B. J Nutr. 2008:138:533-5337.

13. Pérez-Bosque A, Miró L, Polo J, Russell LE, Campbell JM, Weaver E, Crenshaw JD, Moretó M. Dietary plasma protein supplements prevent the release of mucosal proinflammatory mediators in intestinal inflammation in rats. J Nutr. 2010;140:25-30.

14. Cohen S, Miller GE, Rabin BS. Psychological stress and antibody response to immunization: a critical review of the human literature. Psychosom Med. 2001;63:7-18

15. Lambert GP. Stress-induced gastrointestinal barrier dysfunction and its inflammatory effects. J Anim Sci. 2009;87:101-8.

16. Moretó M, Pérez-Bosque A. Dietary plasma proteins, the intestinal immune system, and the barrier functions of the intestinal mucosa. J Anim Sci. 2009; 87:92-100.

17. Yu J, Yin P, Liu F, Cheng G, Guo K, Lu A, Zhu X, Luan W, Xu J. Effect of heat stress on the porcine small intestine: a morphological and gene expression study. Comp Biochem Physiol. 2010;156:119-28.

18. Liptrap RM. Stress and reproduction in domestic animals. Ann N Y Acad Sci. 1993:697:275-84.

19. Einarsson S, Brandt $Y$, Lundeheim N, Madej A. Stress and its influence on reproduction in pigs: a review. Acta Vet Scand. 2008:50(48):1-3.

20. Owusu-Asiedu A, Nyachoti CM, Baidoo SK, Marquardt RR, Yang X. Response of early-weaned pigs to an enterotoxigenic Escherichia coli (K88) challenge when fed diets containing spray-dried porcine plasma or pea protein isolate plus egg yolk antibody. J Anim Sci. 2003;81:1781-9.

21. Owusu-Asiedu A, Nyachoti CM, Marquardt RR. Response of early-weaned pigs to an enterotoxigenic Escherichia coli (K88) challenge when fed diets containing spray-dried porcine plasma or pea protein isolate plus egg yolk antibody, zinc oxide, fumaric acid, or antibiotic. J Anim Sci. 2003:81:1790-8.

22. Yi GF, Carroll JA, Allee GL, Gaines AM, Kendall DC, Usry JL, Toride Y, Izuru S. Effect of glutamine and spray-dried plasma on growth performance, small intestinal morphology, and immune responses of Escherichia coli K88 ${ }^{+}$challenged weaned pigs. J Anim Sci. 2005;83:634-43.

23. NRC. Nutrient requirements of laboratory animals. 4th ed. Washington: The National Academics Press; 1995

24. Balan P, Han KS, Rutherfurd SM, Singh H, Moughan PJ. Orally administered ovine serum immunoglobulins influence growth performance, organ weights, and gut morphology in growing rats. J Nutr. 2008;139:244-9.
25. Yamauchi K, Yamamoto K, Ishiki Y. Morphological alterations of the intestinal villi and absorptive epithelial cells in each intestinal part in fasted chickens. Jpn Poult Sci. 1995;32:241-51.

26. Yamauchi $\mathrm{K}$, Kamisoyama $\mathrm{H}$, Ishiki $\mathrm{Y}$. Effects of fasting and refeeding on structures of the intestinal villi and epithelial cells in white leghorn hens. Br Poult Sci. 1996;37:909-21.

27. Burkholder KM, Thompson KL, Einstein ME, Applegate TJ, Patterson JA. Influence of stressors on normal intestinal microbiota, intestinal morphology, and susceptibility to Salmonella Enteritidis colonization in broilers. Poult Sci. 2008;87:1734-41.

28. Santos J, Saunders PR, Hanssen NP, Yang PC, Yates D, Groot JA, Perdue MH. Corticotropin-releasing hormone mimics stress-induced colonic epithelial pathophysiology in the rat. Am J Phys. 1999;277:391-9.

29. Saunders PR, Kosecka U, McKay DM, Perdue MH. Acute stressors stimulate ion secretion and increase epithelial permeability in rat intestine. Am J Phys. 1994;267:794-9.

30. Nofrarías M, Manzanilla EG, Pujols J, Gibert X, Majó N, Segalés J, Gasa J. Spray-dried porcine plasma affects intestinal morphology and immune cell subsets of weaned pigs. J Anim Sci. 2006;84:2735-42.

\section{Ready to submit your research? Choose BMC and benefit from:}

- fast, convenient online submission

- thorough peer review by experienced researchers in your field

- rapid publication on acceptance

- support for research data, including large and complex data types

- gold Open Access which fosters wider collaboration and increased citations

- maximum visibility for your research: over $100 \mathrm{M}$ website views per year

At BMC, research is always in progress.

Learn more biomedcentral.com/submissions 